\title{
Lack of Communication about Medical Marijuana Use between Doctors and Their Patients
}

\author{
Elin C. Kondrad, MD, Alex J. Reed, PsyD, MPH, Matthew J. Simpson, MD, MPH, \\ and Donald E. Nease, Jr., MD
}

Introduction: Medical marijuana is now permitted in most states, but it is not clear whether primary care physicians (PCPs) are aware of or recommend its use in their patients.

Methods: We distributed paired surveys to PCPs and their patients to assess the frequency of patient marijuana use and communication with PCPs about use.

Results: Of 242 patients surveyed, $22 \%$ reported marijuana use in the past 6 months, and $61 \%$ of these identified as medical marijuana users. PCPs did not complete state forms to recommend medical marijuana for any of the surveyed medical marijuana users. PCPs were aware of marijuana use in their patients only $53 \%$ of the time. PCPs identified conditions they believed could be adversely affected by marijuana use in $31 \%$ of users.

Conclusion: There is poor communication between patients and PCPs about medical marijuana use, which is being sanctioned by physicians other than patients' PCPs. We suggest more frequent assessment of and discussion about marijuana use in patients, particularly in states that have approved medical marijuana. (J Am Board Fam Med 2018;31:805-808.)

Keywords: Communication, Medical Marijuana, Primary Care Physicians, Surveys and Questionnaires

Medical marijuana use is permitted in 28 states and the District of Columbia. ${ }^{1}$ Although people use marijuana for a variety of conditions, the evidence for its benefits is limited in quality and is largely based on studies of synthetic cannabinoids rather than the preparations used by medical marijuana patients. ${ }^{2-6}$ Cannabinoids are also associated with an increased risk of adverse events compared with placebo or other medications. ${ }^{3,4}$

Medical marijuana use may not be identified in routine office screenings for drug use because most users do not consider it a drug of abuse, yet it may also not be identified in medication reconciliation

This article was externally peer reviewed.

Submitted 15 December 2017; revised 18 April 2018; accepted 22 April 2018.

From St. Joseph Family Medicine Residency, Denver, CO (ECK); Department of Family Medicine, University of Colorado School of Medicine, Aurora, CO (AJR, MJS, DEN).

Funding: This research was supported by in-kind support from St. Joseph Family Medicine Residency and the University of Colorado Department of Family Medicine. There were no external funding sources.

Conflict of interest: none declared.

Corresponding author: Elin C. Kondrad, MD, St. Joseph Family Medicine Residency, 1960 Ogden St., Suite 490, Denver, Co 80218 (E-mail: elin.kondrad@sclhs.net). because it is not prescribed and filled at a pharmacy but is recommended and bought at a dispensary. In a 2013 survey of Colorado family physicians, most respondents were skeptical of marijuana's medical benefits and were concerned about adverse effects; fewer than $20 \%$ believed physicians should recommend medical marijuana to patients. ${ }^{7}$ In addition, a small group of physicians are responsible for disproportionately large numbers of medical marijuana recommendations, raising concerns about conflicts of interest among physicians who generate a substantial portion of their income by recommending marijuana. ${ }^{8}$ We sought to assess primary care physicians' (PCPs) awareness of medical marijuana use by their patients and to investigate whether patients received a medical marijuana recommendation in the context of a longitudinal doctor-patient relationship.

\section{Methods}

We performed an observational study in 2013, after Colorado legalized medical marijuana in 2000 but before recreational marijuana sales started in 2014, using a paired "card study" method where medical 
Table 1. Demographics of Patient Participants $(n=294)$ and Reported Marijuana Use in the Past 6 Months

\begin{tabular}{|c|c|c|c|}
\hline & $\begin{array}{l}\text { Marijuana nonusers } \\
\quad(\mathrm{n}=205)\end{array}$ & $\begin{array}{l}\text { Marijuana users } \\
\quad(\mathrm{n}=54)\end{array}$ & $\begin{array}{c}P \text { value } \\
\text { (between group) }\end{array}$ \\
\hline Female, ${ }^{*} \mathrm{n}(\%)$ & $113(55.9)$ & $20(37.7)$ & .018 \\
\hline Male, n (\%) & $89(44.1)$ & $33(62.3)$ & \\
\hline Mean age, ${ }^{\dagger}$ years & 49.7 & 43.9 & \\
\hline White, ${ }^{\ddagger} \mathrm{n}(\%)$ & $117(58.2)$ & $40(76.9)$ & .038 \\
\hline Hispanic, n (\%) & $66(32.2)$ & $9(17.3)$ & \\
\hline Black, n (\%) & $8(3.9)$ & $2(3.8)$ & \\
\hline Asian, n (\%) & $6(2.9)$ & $1(1.9)$ & \\
\hline Native American, n (\%) & $1(0.5)$ & & \\
\hline Other, n (\%) & $3(1.5)$ & & \\
\hline Use marijuana for medical reasons, $\mathrm{n}(\%)$ & N/A & $21(38.9)$ & \\
\hline Use marijuana for recreational reasons, $\mathrm{n}(\%)$ & N/A & $21(38.9)$ & \\
\hline Use marijuana for medical and recreational reasons, $\mathrm{n}(\%)$ & N/A & $12(22.2)$ & \\
\hline
\end{tabular}

N/A, not applicable.

${ }^{*}$ Four people did not indicate their sex (3 in the nonusers group).

${ }^{\dagger}$ One person did not indicate their age.

${ }^{\ddagger}$ Six people did not indicate their race (4 in the nonusers group).

assistants distributed paper surveys linked by corresponding random numbers to patients and their providers during office visits to family medicine clinics. ${ }^{9}$ Patient surveys asked about marijuana use, PCP communication about use, and perceived benefits and adverse effects. Provider surveys asked about patient marijuana use, reasons for use, where the patient obtained a recommendation for medical marijuana, and potential medical benefits and adverse effects. Patients and providers returned surveys in sealed envelopes to a sealed box in the office at the end of the visit. Patient instructions informed them that the survey was voluntary and anonymous. When patients chose not to complete the survey, no data were collected on them and a survey was not given to their provider.

Participating practices included 3 family medicine clinics from the Colorado Research Network in the Denver metro area: 1 university-affiliated practice and 2 Federally Qualified Health Centers. Prisoners, pregnant women, and patients who were mentally disabled, did not speak English, or were under 18 years of age were excluded from the study. The study was approved by the Colorado MultiInstitutional Review Board. Waiver of documentation of written informed consent was granted.

Descriptive statistics were calculated for both patient and provider surveys. Participants were separated into 2 groups based on their self-report of any marijuana use in the previous 6 months. For continuous variables, means were calculated and compared between groups using student's $t$ test for normally distributed variables. Differences in the distributions of categorical variables between the 2 groups were compared using $\chi^{2}$ tests. Two-sided tests were performed, with a significance level of 0.05 selected before analysis. Data were analyzed using IBM SPSS version 24.

\section{Results}

A total of 242 patients completed the survey and 54 (22\%) admitted to marijuana use in the past 6 months. Marijuana users were more likely to be male, white, and of younger age than nonusers (Table 1). Thirty-nine percent of marijuana users (21 patients) reported medical use, 39\% (21 patients) reported recreational use, and 22\% (12 patients) used marijuana both recreationally and medically. Of the 33 medical users, 13 said that their PCP knew about their marijuana use. Fourteen patients reported following up with a doctor about their medical marijuana use, but this was more often with a doctor at a different practice or dispensary (10 patients) than with the patient's PCP (6 patients).

Of the 17 patients reporting a doctor recommendation, 1 patient said that his doctor recommended marijuana, 11 patients said that a doctor at a different office had recommended medical marijuana, and 5 patients said that a doctor at a dispensary had recommended medical marijuana. No pa- 
tients reported that their PCP completed medical marijuana forms for them. Twelve patients reported that forms were completed by a doctor at a different office and 7 patients said that a doctor at a dispensary completed them.

The most common reasons for medical marijuana use were cited as severe pain (45\%), cachexia (19\%), muscle spasms (13\%), and nausea (13\%).

Only $43 \%$ of patients using medical marijuana $(15 / 33)$ responded to questions about perceived risks and benefits of medical marijuana. Of those who did respond, 12 (80\%) said that marijuana was helping the condition for which it was recommended. Only 2 patients (13.3\%) reported adverse effects, while 3 (20\%) were not sure whether marijuana resulted in side effects.

Physicians were aware of marijuana use in 53\% of their patients reporting marijuana use. Seventyseven percent of providers reported that they did not know who had recommended marijuana for the patients they identified as medical marijuana users. No surveyed physicians reported filling out medical marijuana forms for their patients. Physicians identified medical conditions that they felt could be adversely affected by marijuana use (examples were patients with history of mental illness or substance abuse) in $31 \%$ of patients who were marijuana users.

\section{Conclusions}

Our results were consistent with national survey data from the year in which our data were collected, which found that $19.2 \%$ of Coloradans over age 12 reported marijuana use in the past year. ${ }^{10}$ The high percentage of patients reporting concurrent medical and recreational marijuana use was also unsurprising, as prior studies have reported few differences between medical and recreational marijuana users. ${ }^{11}$ During the study time period, the Colorado state medical marijuana registry reported $94 \%$ using marijuana for severe pain, $13 \%$ for muscle spasms, $10 \%$ for nausea, and $1 \%$ for cachexia, so we found higher than expected numbers of patients reporting use for cachexia, whereas the number of people using for severe pain was lower. ${ }^{12}$

Conclusions from this study are limited by its small sample size. The practices surveyed had policies that did not permit physicians to recommend marijuana to patients, which could bias reporting by physicians. Patients and physicians may have felt uncomfortable disclosing use due to stigma surrounding marijuana use. Data on patients' perceived risks and benefits of medical marijuana use are particularly susceptible to bias given the low response rate to these questions. This study was conducted several years ago, but as Colorado began to permit medical marijuana use years before most states (many of which have passed legislation, allowing medical marijuana use since these data were collected), these data remain highly relevant to PCPs nationwide.

Despite these limitations, we believe this study provides valuable information about the limited communication between patients and physicians about medical marijuana use. Although many have embraced the idea of marijuana as a medicine, this study suggests there is rarely an ongoing relationship between patients and the physicians recommending medical marijuana. Those recommendations are being made without input from or communication with a patient's PCP, who knows the patient and his or her medical conditions the best. PCPs are frequently unaware of marijuana use in their patients. When they are aware, most do not know who authorized medical marijuana use for the patient. The lack of communication between patients and their PCPs is particularly concerning because physicians identified medical conditions that could be adversely impacted by marijuana use in almost one-third of patients who were using marijuana. Interestingly, there is discordance between the high level of physician concern about adverse effects and low rates of adverse effects reported by patients.

These findings take on greater significance as awareness of opioid use disorder rises and the need for alternative methods to address chronic pain increases. PCPs should have heightened awareness of the possibility of their patients seeking out marijuana as a source of pain relief. ${ }^{13}$

We suggest that physicians ask patients specifically about marijuana use and engage patients in honest discussions about potential benefits and risks. As is standard for prescribed medications, ongoing assessment of benefits and adverse effects of use should be done with medical marijuana.

The authors would like to acknowledge the efforts of the following people in the development of this project, practice outreach, and study coordination: Colleen Conry, MD; Tillman 
Farley, MD; Douglas Fernald, MA; Lonnie Granston, MD; and Daniel Kortsch.

To see this article online, please go to: bttp://jabfm.org/content/ 31/5/805.full.

\section{References}

1. Carliner H, Brown QL, Sarvet AL, Hasin DS. Cannabis use, attitudes, and legal status in the U.S.: a review. Prev Med 2017;104:13-23.

2. O'Neil ME, Nugent SM, Morasco BJ, et al. Benefits and harms of plant-based cannabis for posttraumatic stress disorder: a systematic review. Ann Intern Med 2017;167:332-40.

3. Nugent SM, Morasco BJ, O’Neil ME, et al. The effects of cannabis among adults with chronic pain and an overview of general harms: a systematic review. Ann Intern Med 2017;167:319-31.

4. Whiting PF, Wolff RF, Deshpande S, et al. Cannabinoids for medical use: a systematic review and meta-analysis. JAMA 2015;313:2456-73.

5. Smith LA, Azariah F, Lavender VTC, Stoner NS, Bettiol S. Cannabinoids for nausea and vomiting in adults with cancer receiving chemotherapy. Cochrane Database Syst Rev 2015;11:CD009464.

6. O'Connell BK, Gloss D, Devinsky O. Cannabinoids in treatment-resistant epilepsy: a review. Epilepsy Behav 2017;70:341-8.
7. Kondrad E, Reid A. Colorado family physicians' attitudes toward medical marijuana. J Am Board Fam Med 2013;26:52-60.

8. Nussbaum AM, Boyer JA, Kondrad EC. "But my doctor recommended pot": medical marijuana and the patient-physician relationship. J Gen Intern Med 2011;26:1364-7.

9. Westfall JM, Zittleman L, Staton EW, et al. Card studies for observational research in practice. Ann Fam Med 2011;9:63-8.

10. Azofeifa A, Mattson ME, Lyerla R. Supplementary Material. State Level Data: Estimates of Marijuana Use and Related Indicators - National Survey on Drug Use and Health, Colorado, 2002-2014. Rockville (MD): Substance Abuse and Mental Health Services Administration; 2016.

11. Roy-Byrne P, Maynard C, Bumgardner K, et al. Are medical marijuana users different from recreational users? The view from primary care. Am J Addict 2015;24:599-606.

12. Colorado Department of Public Health and Environment. Medical marijuana registry program update (as of December 31, 2013). Available from: https://www.colorado.gov/pacific/sites/default/files/ CHED_MMJ_12_2013_MMR_report.pdf. Accessed June 29, 2017.

13. Bradford AC, Bradford WD. Medical marijuana laws may be associated with a decline in the number of prescriptions for Medicaid enrollees. Health Aff (Millwood) 2017;36:945-51. 